\title{
Editorial
}

\section{Smart Learning}

\section{Francisco José García-Peñalvo ${ }^{1, *(\mathbb{D})}$, Cristina Casado-Lumbreras ${ }^{2}$, Ricardo Colomo-Palacios ${ }^{3}[$ and Aman Yadav 4}

1 GRIAL Research Group, Computer Science Department, University of Salamanca, 37008 Salamanca, Spain

2 Research and Psychology in Education Department, Universidad Complutense de Madrid, Pozuelo de Alarcón, 28223 Madrid, Spain; crcasado@ucm.es

3 Department of Computer Science, Østfold University College, 1783 Halden, Norway; ricardo.colomo-palacios@hiof.no

4 Department of Counseling, Educational Psychology and Special Education, Michigan State University, East Lansing, MI 48824, USA; ayadav@msu.edu

* Correspondence: fgarcia@usal.es; Tel.: +34-92-329-4500 (ext. 6095)

Received: 22 September 2020; Accepted: 1 October 2020; Published: 5 October 2020

\begin{abstract}
Artificial intelligence applied to the educational field has a vast potential, especially after the effects worldwide of the COVID-19 pandemic. Online or blended educational modes are needed to respond to the health situation we are living in. The tutorial effort is higher than in the traditional face-to-face approach. Thus, educational systems are claiming smarter learning technologies that do not pretend to substitute the faculty but make their teaching activities easy. This Special Issue is oriented to present a collection of papers of original advances in educational applications and services propelled by artificial intelligence, big data, machine learning, and deep learning.
\end{abstract}

Keywords: artificial intelligence; smart systems; machine learning; deep learning; education; learning technologies; extraction information from educational environments; Internet of Things applied to education; educational data mining; cloud computing in education; data mining and big data analysis; intelligent systems for education; machine and deep learning in education; diagnostic and predictive analytics in educational processes; intelligent process applied in specific educational domains; activity recognition in education; data authentication and security in educational environments; privacy-preserving systems for education; computational models in education

\section{Introduction}

Artificial intelligence has an extensive application area. Nowadays, machine intelligence issues have gone beyond the academic publications to be discussed in closer to general society media such as newspapers, TV shows, etc. [1].

The educational field is not an exception; even artificial intelligence has a very long tradition in supporting the learning processes [2] with intelligent assistants or tutors [3], recommending educational materials [4], predicting students' behaviors [5,6], and managing vast amounts of data [7]. However, big data, machine learning or deep learning techniques provide significant potential for this purpose, leading to new applications, more efficient operations, and more human approaches. These methodologies enable digging massive databases, enhancing the knowledge base and producing new data model-based applications and services for the educational community.

Creating smarter technological learning ecosystems $[8,9]$ has been a shared objective by researchers of computer science and education fields [10]. The concept of smart learning is a learning model based on technology that can detect the students' situation, context, learning needs and style, and the state of their learning process dynamically, and act according to them [11]. Therefore, a smart learning environment is the technology-supported learning environment that makes adaptations and provides 
appropriate support in the right places and at the right time based on individual learners' needs, which might be determined via analyzing their learning behaviors, performance, and the online and real-world contexts in which they are situated [12]. In summary, the smart learning approach is a broad term that includes artificial intelligence-based solutions for developing of the teaching-learning processes with particular focus on their personalization. Many different systems might be considered or classified as smart learning environments, with their specificities and goals, but sharing a common ultimate goal: helping students to learn [13].

The development of smart learning services with the technologies mentioned above will allow advancing to more effective teaching-learning services, with powerful possibilities for teachers and new ways to permit a more self and autonomous for students, with special attention to be used in a mixture of formal and informal learning approaches.

The base for a smart learning system is in data and the needed analytics processes [14]. However, despite the potential advantages associated with automatic analysis of educational data, important questions arise, primarily related to the ethical and privacy $[15,16]$ aspects of the teaching-learning process.

The smart learning aborded topic has a continuous interest; however, the worldwide pandemic due to COVID-19 disease has shed light on distance learning technologies and online or blended teaching and learning methodologies [17-19]. Moreover, the human effort, the digital alphabetization, and the existing digital divides of both teachers and students, to change or adapt the face-to-face teaching and learning methods to online-based ones, are significant [20]. The work done to close the 2019-2020 course was an emergency action [21], but the disease has not disappeared; thus, governments, academic institutions, faculty, students, and families have to tackle with a very uncertain situation. Artificial Intelligence may help develop and deploy smarter learning technological-based ecosystems, which do not pretend to substitute the teachers within this process but help and support them with more robust and intelligent services to make easy the follow-up, tutorial, and feedback, etc., activities [22]. The final objective is not only to reduce the teaching effort but to increase the learning possibilities of the student with more significant learning technologies. If these goals are achieved, these smarter learning ecosystems will remain in the Education habits far away from the COVID-19 pandemic, achieving an educational transformation in which the educational methodologies will be more efficient based on the technologies used.

\section{A Review of the Contributions in this Special Issue}

This Special Issue is oriented to present a collection of 18 papers of original advances in educational applications and services propelled by artificial intelligence, big data, machine learning, and deep learning.

Learning analytics processes [23] support educational stakeholders to make decisions about the academic institutions in a broad sense or the classroom context. Extracting the right data and transforming it into valuable information is key to building smarter processes within the educational realm, such as diagnostic and predictive analysis [24]. Liz-Domínguez et al. [25] do a systematic literature review, following PRISMA guidelines [26], of predictive analysis tools in higher education, highlighting the most relevant instances of predictors and early warning systems used in practice. Sáiz-Manzanares et al. [27] introduce a Moodle plug-in, so-called eOrientation, to detect at-risk students, which is used in junction with a learning analytics module, through which both supervised and unsupervised machine learning techniques can be applied. Moreno-Marcos et al. [28] propose analyzing and measuring two types of persistence based on students' interactions in online courses: (1) local persistence (based on the attempts used to solve an exercise when the student answers it incorrectly), and (2) global persistence (based on overall course activity/completion). Chaparro-Peláez et al. [29] details the architecture design, configuration, and use of the Moodle Workshop Data Extractor application, and proposes an initial validation of the tool based on the current peer assessment practices of a group of learning analytics experts. 
Models are essential tools in computing and software engineering [30] that may also be applied in different educational domains. Im et al. [31] make a study to define the affective level of a given set of paragraphs and attempts to analyze the perceived trust of the methodologies in regard to usability. Vázquez-Ingelmo et al. [32] define an information dashboard [33] metamodel that abstracts all these factors and integrates a visualization task taxonomy to account for the different actions that can be performed with information dashboards. This metamodel may be used to design a domain-specific language to specify dashboards' requirements in a structured way [34]. Grivokostopoulou et al. [35] model 3D virtual worlds the domain of environmental engineering and energy generation, including intelligent pedagogical agents, to enhance students' interaction and improve their overall learning experience. Authors want to examine and deeply understand the effect that embodied pedagogical agents have on students' learning experience and their performance.

To personalize learning [36], it is mandatory to characterize activities for further recognition and make models of the learners [37]. Real-Fernández et al. [38] propose that the students are characterized based on their system activity instead of on self-reporting. The vectors are data structures formed by numerical or categorical variables such as learning style, cognitive level, knowledge type, or the history of the learner's actions in the system, which are computed by artificial intelligence algorithms.

Since the early 1980s, researchers have developed intelligent tutoring systems looking for the introduction of the artificial intelligence in education [39]. Subirats et al. [40] introduce a tutoring system that uses three different granularities to help students classify animals from bone fragments in zooarchaeology. The 3406 bone remains, which have 64 attributes, were obtained from an excavation of the Middle Paleolithic. The research done demonstrated the usefulness of the tutoring system for students when facing their first classification activities and seniors since the tutoring system gives them valuable clues for helping in difficult classification problems. Schez-Sobrino et al. [41] develop an intelligent tutoring system for support students on learning programming by using a notation based on a metaphor of roads and traffic signs represented by 3D graphics in an augmented reality environment.

Nevertheless, intelligent tutoring systems are not the only intelligent systems that are used in education. There many more kinds of intelligent platforms that might be considered as smart learning environments [42]. Nieto-Márquez et al. [43] explore the Smile and Learn intelligent platform's usage in three pilot groups schools from different regions of Spain, outlining future directions in the design of digital materials. The results show high use of STEM (Science, Technology, Engineering, and Maths) activities [44] among all the activities that could be chosen.

Assessment is one of the most complex online education activities $[45,46]$; thus, smart services that support teachers' evaluation processes are needed. The contribution of Ramanauskaite and Slotkiene [47] is devoted to making an empirical study to adapt the competency tree design and application for competencies e-evaluation method, based on flexibility, adaptability, and granularity of learning material. Guerrero-Higueras et al. [48] show a methodology that uses several machine learning models' performances to select the appropriate predicting model for assessing the students' achievements based on their interactions with a version control system in computer science subjects. Melesko and Novickij [49] tackle the formative assessment defining an approach based on a Multi-Armed bandit problem that uses the Upper-Confidence Bound algorithm in adaptive tests.

Cloud services are expandable and on-demand that are served via the Internet from specialized data centers. Cloud service delivery is usually represented by three classifications that are often referred to as the SPI Model, where SPI refers to Software, Platform or Infrastructure (as a Service), denoted in the literature as the acronyms SaaS, PaaS, and IaaS, respectively. Cloud services have a significant and growing presence in educational institutions seeking to reduce their information technology and maintenance budgets as well as increasing the number of quality services with easier accessibility and more user experience [50], which is translated into higher levels of perceived usefulness of faculty and students [51]. Tobarra et al. [52] present and evaluate a virtual laboratory based on Linux Docker virtualization technology, which allows us to create consistent realistic scenarios with lower configuration requirements for the students about the cybersecurity topic. 
Internet of Things technologies are motivating institutions for digital transformation [53]. In the NMC Horizon Report, the impact of current and future technologies on education, mentioned the Internet of Things the first time in its 2012 edition [54]. Fernández-Caramés and Fraga-Lamas [55] review the state of the start on the application of the Blockchain [56], Internet of Things [57], Fog [58], and Edge Computing [59] technologies to develop smart campuses and universities. Sretenovic et al. [60] introduces a laboratory for biometric engineering education, which allows students to learn more about fingerprint acquisition and analyze the impact of the acquisition on other parts of the biometric authentication process with an Internet of Things approach. Santos Pereira et al. [61] evaluate and compare the current state of digital adoption in terms of the preparation according to the prevailing technological categories (pillars and innovation accelerators) and future priorities of organizations in the implementation of digital transformation in Portuguese organizations.

Author Contributions: Writing of the Editorial paper, F.J.G.-P.; conceptualization of the special issue, F.J.G.-P., C.C.-L., R.C.-P., A.Y.; performing and management of the special issue, F.J.G.-P., C.C.-L., R.C.-P., A.Y.; reviewing the Editorial paper C.C.L., R.C.-P, A.Y. All authors have read and agreed to the published version of the manuscript.

Funding: This research was partially funded by the Spanish Government Ministry of Economy and Competitiveness throughout the DEFINES project grant number [TIN2016-80172-R].

Acknowledgments: This issue would not be possible without the authors' contributions, reviewers, and dedicated editorial team of Applied Sciences. Congratulations to all authors, no matter what the submitted manuscripts' final decisions were, the feedback, comments, and suggestions from the reviewers and editors helped the authors improve their papers. Finally, we send our gratitude to the editorial team of Applied Sciences for their constant support.

Conflicts of Interest: The authors declare no conflict of interest.

\section{References}

1. Moreno, L.; Pedreño, A. Europa Frente a EE. UU. y China: Prevenir el Declive en la Era de la Inteligencia Artificial; University of Alicante: Alicante, Spain, 2020.

2. Yu, Z. Visualizing Artificial Intelligence Used in Education Over Two Decades. J. Inf. Technol. Res. $2020,13$.

3. Martens, A.; Uhrmacher, A.M. Adaptive tutoring processes and mental plans. In Intelligent Tutoring Systems, Proceedings of the 6th International Conference, ITS 2002, Biarritz, France; San Sebastian, Spain, 2-7 June 2002; Lecture Notes in Computer Science; Cerri, S.A., Gouardères, G., Paraguaçu, F., Eds.; Springer: Berlin/Heidelberg, Germany, 2002; pp. 71-80.

4. Ammar, W.B.H.; Chaabouni, M.; Ghezala, H.B. Recommender system for quality educational resources. In Intelligent Tutoring Systems, Proceedings of the 16th International Conference, ITS 2020, Athens, Greece, 8-12 June 2020; Lecture Notes in Computer Science; Kumar, V., Troussas, C., Eds.; Springer International Publishing: Cham, Switzerland, 2020; pp. 327-334.

5. Waheed, S.-U.H.; Hassan, N.; Aljohani, R.; Hardman, J.; Alelyani, S.; Nawaz, R. Predicting academic performance of students from VLE big data using deep learning models. In Computers in Human Behavior; Elsevier: Amsterdam, The Netherlands, 2020; Volume 104, p. 106189. [CrossRef]

6. Huang, A.Y.-Q.; Lu, O.H.T.; Huang, J.C.H.; Yin, C.J.; Yang, S.J.H. Predicting students' academic performance by using educational big data and learning analytics: Evaluation of classification methods and learning logs. Interact. Learn. Environ. 2019, 28, 206-230. [CrossRef]

7. Daniel, B.K. Big Data and data science: A critical review of issues for educational research. Br. J. Educ. Technol. 2017, 50, 101-113. [CrossRef]

8. García-Holgado, A.; García-Peñalvo, F.J. A metamodel proposal for developing learning ecosystems. In Learning and Collaboration Technologies; Novel Learning Ecosystems; no. 10295; Proceedings of the 4th International Conference, LCT 2017, Vancouver, BC, Canada, 9-14 July 2017; Lecture Notes in Computer Science; Held as Part of HCI International 2017; Part I; Zaphiris, P., Ioannou, A., Eds.; Springer International Publishing: Cham, Switzerland, 2017; pp. 100-109.

9. Garcia-Holgado, A.; García-Peñalvo, F.J. Validation of the learning ecosystem metamodel using transformation rules. Future Gener. Comput. Syst. 2019, 91, 300-310. [CrossRef]

10. Hwang, G.-J. Definition, framework and research issues of smart learning environments-A context-aware ubiquitous learning perspective. Smart Learn. Environ. 2014, 1, 492. [CrossRef] 
11. Molina-Carmona, R.; Villagrá-Arnedo, C.J. Smart learning. In TEEM'18: Sixth Edition Technological Ecosystems for Enhancing Multiculturality, Proceedings of the Sixth International Conference on Technological Ecosystems for Enhancing Multiculturality, Salamanca, Spain, 24-26 October 2018; García-Peñalvo, F.J., Ed.; ACM: New York, NY, USA, 2018; pp. 645-647.

12. Hwang, G.-J.; Tsai, C.-C.; Yang, S.J.H. Criteria, Strategies and Research Issues of Context-Aware Ubiquitous Learning. J. Educ. Technol. Soc. 2008, 11, 81-91.

13. Molina-Carmona, R.; Villagrá-Arnedo, C.J. Advances in smart learning. In TEEM'19, Proceedings of the Seventh International Conference on Technological Ecosystems for Enhancing Multiculturality, Leon, Spain, 16-18 October 2019; ICPS: ACM International Conference Proceedings Series; Conde-González, M.Á., Rodríguez-Sedano, F.J., Fernández-Llamas, C., García-Peñalvo, F.J., Eds.; ACM: New York, NY, USA, 2019; pp. 649-652.

14. García-Peñalvo, F.J. Learning Analytics as a Breakthrough in Educational Improvement. In Radical Solutions and Learning Analytics: Personalised Learning and Teaching Through Big Data; Lecture Notes in Educational, Technology; Burgos, D., Ed.; Springer: Singapore, 2020; pp. 1-15.

15. Alier-Forment, M.; Amo-Filvà, D.; García-Peñalvo, F.J.; Fonseca-Escudero, D.; Casañ, M.J. Learning analytics' privacy on the blockchain. In TEEM'18: Sixth Edition Technological Ecosystems for Enhancing Multiculturality, Proceedings of the Sixth International Conference on Technological Ecosystems for Enhancing Multiculturality, Salamanca, Spain, 24-26 October 2018; García-Peñalvo, F.J., Ed.; ACM: New York, NY, USA, 2018; pp. $294-298$.

16. Amo, D.; Alier, M.; García-Peñalvo, F.J.; Fonseca, D.; Casañ, M.J. Protected Users: A Moodle Plugin to Improve Confidentiality and Privacy Support through User Aliases. Sustainability 2020, 12, 2548. [CrossRef]

17. García-Peñalvo, F.J.; Corell, A. La COVID-19: ¿Enzima de la transformación digital de la docencia o reflejo de una crisis metodológica y competencial en la educación superior? Campus Virtuales 2020, 9.

18. García-Peñalvo, F.J.; Corell, A.; Abella-García, V.; Grande, M. La evaluación online en la educación superior en tiempos de la COVID-19. Educ. Knowl. Soc. 2020, 21, 12. [CrossRef]

19. Habib, H.; González, C.; Collazos, C.A.; Yousef, M. Estudio exploratorio en iberoamérica sobre procesos de enseñanza-aprendizaje y propuesta de evaluación en tiempos de pandemia. Educ. Knowl. Soc. 2020, 21, 17. [CrossRef]

20. Daniel, S.J. Education and the COVID-19 pandemic. Prospects 2020. [CrossRef] [PubMed]

21. Hodges, C.; Moore, S.; Lockee, B.; Trust, T.; Bond, A. The Difference between Emergency Remote Teaching and Online Learning. In Educause Review. Available online: https://bit.ly/3b0Nzx7 (accessed on 3 October 2020).

22. Tinoco-Giraldo, H.; Sánchez, E.M.T.; García-Peñalvo, F.J. E-Mentoring in Higher Education: A Structured Literature Review and Implications for Future Research. Sustainability 2020, 12, 4344. [CrossRef]

23. Siemens, G. Learning Analytics. The Emergence of a Discipline. Am. Behav. Sci. 2013, 57, 1380-1400. [CrossRef]

24. Uskov, V.L.; Bakken, J.P.; Byerly, A.; Shah, A. Machine learning-based predictive analytics of student academic performance. In STEM Education, Proceedings of the 2019 Global Engineering Education Conference (EDUCON), Dubai, United Arab Emirates, 8-11 April 2019; IEEE: Piscataway, NJ, USA, 2019; pp. 1370-1376.

25. Liz-Domínguez, M.; Rodríguez, M.C.; Llamas-Nistal, M.; Mikic-Fonte, F.A. Systematic Literature Review of Predictive Analysis Tools in Higher Education. Appl. Sci. 2019, 9, 5569. [CrossRef]

26. Liberati, A.; Altman, D.G.; Tetzlaff, J.; Mulrow, C.; Gøtzsche, P.C.; Ioannidis, J.P.A.; Clarke, M.; Devereaux, P.J.; Kleijnen, J.; Moher, D. The PRISMA Statement for Reporting Systematic Reviews and Meta-Analyses of Studies That Evaluate Health Care Interventions: Explanation and Elaboration. PLoS Med. 2009, 6, e1000100. [CrossRef]

27. Sáiz-Manzanares, M.C.; Marticorena-Sánchez, R.; García-Osorio, C. Monitoring Students at the University: Design and Application of a Moodle Plugin. Appl. Sci. 2020, 10, 3469. [CrossRef]

28. Moreno-Marcos, P.M.; Muñoz-Merino, P.J.; Alario-Hoyos, C.; Kloos, C.D. Re-Defining, Analyzing and Predicting Persistence Using Student Events in Online Learning. Appl. Sci. 2020, 10, 1722. [CrossRef]

29. Chaparro-Peláez, J.; Iglesias-Pradas, S.; Rodríguez-Sedano, F.J.; Acquila-Natale, E. Extraction, Processing and Visualization of Peer Assessment Data in Moodle. Appl. Sci. 2019, 10, 163. [CrossRef]

30. Seidewitz, E. What models mean. IEEE Softw. 2003, 20, 26-32. [CrossRef]

31. Im, Y.; Park, J.; Kim, M.; Park, K. Comparative Study on Perceived Trust of Topic Modeling Based on Affective Level of Educational Text. Appl. Sci. 2019, 9, 4565. [CrossRef] 
32. Vázquez-Ingelmo, A.; García-Peñalvo, F.J.; Theron, R.; Conde-González, M. Ángel Representing Data Visualization Goals and Tasks through Meta-Modeling to Tailor Information Dashboards. Appl. Sci. 2020, 10, 2306. [CrossRef]

33. Vázquez-Ingelmo, A.; Garcia, B.A.; Theron, R. Information Dashboards and Tailoring Capabilities-A Systematic Literature Review. IEEE Access 2019, 7, 109673-109688. [CrossRef]

34. Vázquez-Ingelmo, A.; García-Peñalvo, F.J.; Theron, R.; Filvà, D.A.; Escudero, D.F. Connecting domain-specific features to source code: Towards the automatization of dashboard generation. Clust. Comput. J. Netw. Softw. Tools Appl. 2019, in press. [CrossRef]

35. Grivokostopoulou, F.; Kovas, K.; Perikos, I. The Effectiveness of Embodied Pedagogical Agents and Their Impact on Students Learning in Virtual Worlds. Appl. Sci. 2020, 10, 1739. [CrossRef]

36. Walkington, C.; Bernacki, M.L. Appraising research on personalized learning: Definitions, theoretical alignment, advancements, and future directions. J. Res. Technol. Educ. 2020, 52, 235-252. [CrossRef]

37. Hlioui, F.; Alioui, N.; Gargouri, F. A survey on learner models in adaptive E-learning systems. In Proceedings of the 13th International Conference of Computer Systems and Applications (AICCSA), Agadir, Morocco, 29 November-2 December 2016; IEEE: Piscataway, NJ, USA, 2016.

38. Real-Fernández, A.; Molina-Carmona, R.; Llorens, F. Computational Characterization of Activities and Learners in a Learning System. Appl. Sci. 2020, 10, 2208. [CrossRef]

39. Sleeman, D.; Brown, J.S. Intelligent Tutoring Systems; Academic Press: London, UK, 1982.

40. Subirats, L.; Pérez, L.; Hernández, C.M.; Fort, S.; Sacha, G.M. A Granularity-Based Intelligent Tutoring System for Zooarchaeology. Appl. Sci. 2019, 9, 4960. [CrossRef]

41. Schez-Sobrino, S.; Gmez-Portes, C.; Vallejo, D.; Glez-Morcillo, C.; Redondo, M.Á. An Intelligent Tutoring System to Facilitate the Learning of Programming through the Usage of Dynamic Graphic Visualizations. Appl. Sci. 2020, 10, 1518. [CrossRef]

42. Chen, N.S.; Cheng, I.L.; Chew, S.W. Evolution Is not enough: Revolutionizing Current Learning Environments to Smart Learning Environments. Int. J. Artif. Intell. Educ. 2016, 26, 561-581. [CrossRef]

43. Nieto-Márquez, N.L.; Baldominos, A.; Martínez, A.C.; Perez-Nieto, M.A. An Exploratory Analysis of the Implementation and Use of an Intelligent Platform for Learning in Primary Education. Appl. Sci. 2020, 10, 983. [CrossRef]

44. García-Peñalvo, F.J.; Bello, A.; Dominguez, A.; Romero, R.M. Acciones, políticas y estrategias para el balance de género en el ámbito STEM: Resultados de una dinámica World Café. Educ. Knowl. Soc. 2019, 20, 15. [CrossRef]

45. Gikandi, J.; Morrow, D.; Davis, N. Online formative assessment in higher education: A review of the literature. Comput. Educ. 2011, 57, 2333-2351. [CrossRef]

46. González-González, C.; Moro, A.I.; Moro, A.I. Implementation of E-Proctoring in Online Teaching: A Study about Motivational Factors. Sustainability 2020, 12, 3488. [CrossRef]

47. Zhong, B.; Wang, Q.; Chen, J.; Li, Y. An Exploration of Three-Dimensional Integrated Assessment for Computational Thinking. J. Educ. Comput. Res. 2015, 53, 562-590. [CrossRef]

48. Guerrero-Higueras Ángel, M.; Fernández-Llamas, C.; Sánchez-González, L.; Fernández, A.G.; Costales, G.E.; González, M.A.C. Academic Success Assessment through Version Control Systems. Appl. Sci. 2020, 10, 1492. [CrossRef]

49. Melesko, J.; Novickij, V. Computer Adaptive Testing Using Upper-Confidence Bound Algorithm for Formative Assessment. Appl. Sci. 2019, 9, 4303. [CrossRef]

50. Pardeshi, V.H. Cloud Computing for Higher Education Institutes: Architecture, Strategy and Recommendations for Effective Adaptation. Procedia Econ. Finance 2014, 11, 589-599. [CrossRef]

51. Stantchev, V.; Colomo-Palacios, R.; Soto-Acosta, P.; Misra, S. Learning management systems and cloud file hosting services: A study on students' acceptance. Comput. Hum. Behav. 2014, 31, 612-619. [CrossRef]

52. Tobarra, L.; Robles-Gómez, A.; Pastor-Vargas, R.; Hernández, R.; Duque, A.; Cano, J. Students' Acceptance and Tracking of a New Container-Based Virtual Laboratory. Appl. Sci. 2020, 10, 1091. [CrossRef]

53. Kang, B.; Kim, D.; Choo, H. Internet of Everything: A Large-Scale Autonomic IoT Gateway. IEEE Trans. Multi Scale Comput. Syst. 2017, 3, 206-214. [CrossRef]

54. Johnson, L.; Adams, S.; Cummins, M. The NMC Horizon Report: 2012 Higher Education Edition; The New Media Consortium: Austin, TX, USA, 2012. 
55. Fernández-Caramés, T.M.; Fraga-Lamas, P. Towards Next Generation Teaching, Learning, and Context-Aware Applications for Higher Education: A Review on Blockchain, IoT, Fog and Edge Computing Enabled Smart Campuses and Universities. Appl. Sci. 2019, 9, 4479. [CrossRef]

56. Turcu, C.; Turcu, C.; Chiuchisan, I. Blockchain and its Potential in Education. In Proceedings of the International Conference on Virtual Learning-ICVL 2018, Alba Iulia, Romania, 26-28 October 2018.

57. Atzori, L.; Iera, A.; Morabito, G. The Internet of Things: A survey. Comput. Netw. 2010, 54, $2787-2805$. [CrossRef]

58. Bonomi, F.; Milito, R.; Zhu, J.; Addepalli, S. MCC'12: Proceedings of the First Edition of the MCC Workshop on Mobile Cloud Computing, Proceedings of the SIGCOMM'12: ACM SIGCOMM 2012 Conference, Helsinki, Finland, August 2012; ACM: New York, NY, USA, 2012; pp. 13-16.

59. Satyanarayanan, M. The Emergence of Edge Computing. Computer 2017, 50, 30-39. [CrossRef]

60. Sretenovic, M.B.; Milenkovic, I.; Jovanovic, B.; Simic, D.; Minovic, M.; Milovanovic, M. Bringing Biometric Sensors to the Classroom: A Fingerprint Acquisition Laboratory for Improving Student Motivation and Commitment. Appl. Sci. 2020, 10, 880. [CrossRef]

61. Pereira, C.S.; Durão, N.; Fonseca, D.; Ferreira, M.J.; Moreira, F. An Educational Approach for Present and Future of Digital Transformation in Portuguese Organizations. Appl. Sci. 2020, 10, 757. [CrossRef]

(C) 2020 by the authors. Licensee MDPI, Basel, Switzerland. This article is an open access article distributed under the terms and conditions of the Creative Commons Attribution (CC BY) license (http://creativecommons.org/licenses/by/4.0/). 